\title{
An experimental investigation into the salt-weathering susceptibility of building limestones
}

\author{
Simona Scrivano ${ }^{1}$ (i) $\cdot$ Laura Gaggero ${ }^{1}$
}

Received: 20 November 2019 / Accepted: 17 July 2020 / Published online: 10 September 2020

(c) The Author(s) 2020

\begin{abstract}
Dimension and ornamental stones used for built heritage are frequently affected, under all climates, by intense weathering induced by the transport of saline solutions. Accordingly, researchers addressed the weathering mechanisms induced by salts (primarily $\mathrm{Na}_{2} \mathrm{SO}_{4}$ ), the stresses generated in the host material, and the durability of ornamental and dimension stones. This study investigates the behaviour of four sedimentary lithotypes, differing in texture and structure (Breccia Aurora, Rosso Verona, and fine- and coarse-grained Vicenza Stone) exposed to a selection of saline solutions, aiming at evaluating their susceptibility to weathering and the influence of petrographic features on durability. The chosen $\mathrm{Na}_{2} \mathrm{SO}_{4}, \mathrm{MgSO}_{4}, \mathrm{Na}_{2} \mathrm{CO}_{3}$, $\mathrm{NaCl}$, and $\mathrm{KNO}_{3}$ solutions include the anions characterizing the major saline sources affecting built heritage: capillary rise, acid rain, atmospheric particulate deposition, bird or other animal scat, and de-icing salt contamination.

The petrophysical properties of unweathered and salt-weathered samples were characterized by relative mass variation estimation, capillary rise, and hygroscopic absorption-based porosimetry. Scanning Electron Microscopy coupled with microprobe allowed studying the morphological changes triggered by weathering and analysing the chemical composition of the efflorescence crust.

The whole of data, consistently with literature, allowed inferring pore type and distribution as the main intrinsic parameters controlling salt weathering susceptibility. Moreover, $\mathrm{Na}_{2} \mathrm{SO}_{4}$ and $\mathrm{Na}_{2} \mathrm{CO}_{3}$ proved to be the most harmful, probably due to their ability to crystallize in different hydration stages at room temperature. The comparative analysis of the induced weathering can help to choose suitable dimension stones for new buildings or restoration replacements.
\end{abstract}

Keywords Salt weathering $\cdot$ Limestones $\cdot$ Pore network $\cdot$ Salt susceptibility $\cdot$ Dimension stones

\section{Introduction}

Within natural materials, dimension stones in monumental structures and artefacts are studied correlating mineralogicpetrographic and petrophysical characteristics to durability. The added cultural value encourage to study these materials to understand weathering phenomena and the response of each material to diverse environmental parameters, to preserve them (Török and Přikryl 2010).

Salt crystallization has a significant effect on the weathering of exposed ornamental and building stones (Amoroso and Fassina 1983; Siegesmund and Snethlage 2014). The significance of soluble salts as weathering agents derives

Simona Scrivano

simona.scrivano@edu.unige.it

1 Department of Earth, Environment and Life Sciences, University of Genoa, C.so Europa 26, 16132 Genoa, Italy from their ubiquitous occurrence in a wide range of environments (e.g., urban, desert, coastal, and rural; Goudie and Viles 1997; Smith et al. 2005), and their activity under wide ranges of relative humidity and temperature (Puehringer 1983; Sun and Zhang 2019). Therefore, proper conservation of stone artefacts relies on understanding the parameters involved in salt weathering, in particular the role of salt crystallization (Çelik and Aygün 2019).

Crystallization is the process common to all salt species inducing weathering in the host stone. The most common model considers a saline solution circulating inside the pore network, where salt precipitation begins when water starts to evaporate or temperature raises (Cardell et al. 2008; Castellazzi et al. 2013; Grementieri et al. 2017). This process occurs where the dynamic balance between evaporation rate and solution supply rate slows down or ceases. The evaporation rate depends on rock properties (permeability and pore size) and on environmental conditions (relative 
humidity, RH; temperature, T; Cardell et al. 2003; Grementieri et al. 2017). The supply rate depends on the properties of the solution (flux, surface tension, contact angle, viscosity) and of the rock core (permeability, pore size, and path length; Scherer 2004). If the evaporation rate is lower than the solution supply rate, then crystallization occurs at the material surface, causing the formation of efflorescence. If the evaporation rate is higher than the solution supply rate, then salts precipitate within the pore network, causing subefflorescence and mechanical damage.

Previous studies have focused primarily on crystallization pressure (Flatt 2002; Scherer 2004; Steiger 2005), thermal expansion (Ruedrich and Siegesmund 2007), hydraulic pressure (McMahon et al. 1992), wetting-drying pairs (Sun and Zhang 2019) and chemical weathering caused by the dissolution of minerals with weaker ionic strength than that of the saline solution (Cardell et al. 2003). These processes may all be valid and possibly co-occur, however, the most significant is the crystallization pressure. Crystal formation is favoured in larger pores, and once space is filled with a crystal, the residual solution in the smaller neighbouring capillary is affected by a curvature change due to a change decrease ? in saturation, and maximum pressure is exerted on pore walls (Steiger 2005). All the available models underline the importance of pore size and shape as a sink for salt contamination (Everett 1961; Fitzner and Snethlage 1982; Nicholson 2001; Flatt 2002; Benavente et al. 2004a, b; Angeli et al. 2008; Yu and Oguchi 2010).

To monitor the weathering induced by saline solutions, several petrophysical characteristics could be taken into account, including (i) pore size distribution (Ordóñez et al. 1997; Prikryl et al. 2003; Yu and Oguchi 2010; Akin and Özsan 2011; Di Benedetto et al. 2015), (ii) effective porosity (Yavuz and Topal 2007), (iii) water absorption by capillary uptake and total immersion (Dessandier 2000; Benavente et al. 2006), (iv) ultrasound velocity (Nicholson 2001, 2002; Sousa et al. 2005; Alonso et al. 2008; Ceryan et al. 2008), and (v) weight loss (Zedef et al. 2007).

Sulphates, chlorides, carbonates, and nitrates, combined with different cations $\left(\mathrm{Na}^{+}, \mathrm{K}^{+}, \mathrm{Mg}^{2+}, \mathrm{Ca}^{2+}\right.$, and $\left.\mathrm{NH}_{4}^{+}\right)$, are the most common trigger for deterioration in dimension stones (Siegesmund and Snethlage 2014). Also deterioration caused by alums, nitrites, and oxalates have been reported (Arnold and Kueng 1985; Arnold and Zehnder 1990). Identification of the dissolved anions is crucial to interpret the origin of contamination: carbonates and sulphates can originate from rock-forming minerals, circulating water, dissolution of mortars, or pollution. Chlorides are present in coastal environments and organic matter and, rarely, as a result of the salt-storage-function of a building. Nitrates are typical of organic-matter-rich water and phosphates of water containing fertilizers or bone matter. The presence of oxalates indicates the reaction of minerals with organic matter, usually with artificial products for stone conservation treatment. Unlike anions, the identification of cations is not fundamentally important to the interpretation of the origin of weathering phenomena.

The susceptibility of diverse lithotypes to salt weathering has been studied through different, more or less standardized, ageing procedures (Lubelli et al. 2018). Usually, to reduce the number of variables (e.g., concentration of solutes, chemical interactions, environmental variables; Angeli et al. 2010), contamination by a single saline solution is considered. However, water in the pore network contains more than one species of solute, that consequently interact (Cardell et al. 2008). Some studies have considered several solute-species mixtures, but no reliable model was derived because of the numerous concurring variables (Arnold 1981; Robinson and Williams 2000).

Based on the literature review carried out by the RILEM technical committee 271 ASC (Lubelli et al. 2018), the continuous partial immersion test method (Benavente et al. 2001) was used to assess the behaviour of a selection of saline solutions. Saline solutions $\left(\mathrm{Na}_{2} \mathrm{SO}_{4}, \mathrm{MgSO}_{4}, \mathrm{Na}_{2} \mathrm{CO}_{3}\right.$, $\mathrm{NaCl}$, and $\mathrm{KNO}_{3}$ ) were applied to several well-characterized lithotypes; then, diffusion and physical behaviour (hygroscopicity and potential hydrate formation) were analysed and compared.

The study was carried out on a selection of rocks with homogeneous mineralogical composition but differing in texture and structure. The analysed lithotypes are all limestones employed as building or ornamental stones, and are characterized by different structural features due to their petrogenesis (Scrivano et al. 2018). Limestones are widespread as ornamental stones, but their mineralogical composition (mainly $\mathrm{CaCO}_{3}$ ) makes them liable to weathering processes, being calcite highly soluble in acidic waters (Schiro et al. 2012).

Five different saline solutions were designed to identify whether salt precipitation induces chemical interactions within the analysed stones and to evaluate its importance with respect to mechanical stress induced by crystallization. $\mathrm{Na}_{2} \mathrm{SO}_{4}, \mathrm{MgSO}_{4}, \mathrm{Na}_{2} \mathrm{CO}_{3}, \mathrm{NaCl}$, and $\mathrm{KNO}_{3}$ saline solutions were selected based on the mineral phases observed in efflorescence in real case studies (Arnold and Zehnder 1991; Siegesmund and Snethlage 2014; Siedel 2018). Moreover, $\mathrm{Na}_{2} \mathrm{SO}_{4}$ is normally used in determining stone durability to salt decay for its presence in acid rains and its highly destructive impact on stone structure (UNI EN 12, 370: 2001; UNI EN 13, 919: 2002; McMahon et al. 1992; Tsui et al. 2003; Ruiz-Agudo et al. 2007; Angeli et al. 2008, 2010; Diaz Gonçalves and Brito 2014). Ruiz-Agudo et al. 2007; Akin and Özsan 2011 report also the use of $\mathrm{MgSO}_{4}$ in testing stone resistance. In this study, this saline solution was used because it forms minerals with different hydration state (epsomite: $\mathrm{MgSO}_{4} 7 \mathrm{H}_{2} \mathrm{O}$; hexahydrate: $\mathrm{MgSO}_{4} 6 \mathrm{H}_{2} \mathrm{O}$; 
pentahydrate: $\mathrm{MgSO}_{4} \cdot 5 \mathrm{H}_{2} \mathrm{O}$; and starkeyite: $\mathrm{MgSO}_{4} \cdot 4 \mathrm{H}_{2} \mathrm{O}$ ). The same behaviour characterizes also $\mathrm{Na}_{2} \mathrm{SO}_{4}$ (mirabilite: $\mathrm{Na}_{2} \mathrm{SO}_{4} \cdot 10 \mathrm{H}_{2} \mathrm{O}$; thenardite: $\mathrm{Na}_{2} \mathrm{SO}_{4}$ ) and $\mathrm{Na}_{2} \mathrm{CO}_{3}$ (natron: $\mathrm{Na}_{2} \mathrm{CO}_{3} \cdot 10 \mathrm{H}_{2} \mathrm{O}$; thermonatrite: $\mathrm{Na}_{2} \mathrm{CO}_{3} \cdot \mathrm{H}_{2} \mathrm{O}$ ) solutions, evidencing the influence of environmental conditions in the salt weathering process. Low solubility characterizes nitrates, that easily occur as efflorescence (Siegesmund and Snethlage 2014), and $\mathrm{KNO}_{3}$ was selected to represent the chemical activity of nitrate compounds. Finally, also a $\mathrm{NaCl}$ solution was used, as in material testing procedures (UNI EN 14, 147:2003), to recreate sea spray effect on stone artefacts.

The objective of the study was to investigate the weathering mechanisms from different saline solutions, and to evaluate the influence of mineralogical and textural features on the degree of salt weathering, i.e. the control of petrophysical features on the durability of the analysed ornamental and dimension stone. Moreover, as each of the tested saline solutions represents specific environmental agents, the response of the lithotypes helps the selection of the dimension stones for diverse uses. For example, a pronounced susceptibility of a lithotype to $\mathrm{NaCl}$ advises against its use in a coastal environment.

Moreover, the study aims at deciphering the interaction between the solutes and the intrinsic textural and structural weaknesses of the chosen lithotypes. The identification of thisbehavioural pattern could help establishing protocols useful to define conservation strategies. For example, recognizing the features influencing susceptibility to a certain type of solution can be crucial in choosing the appropriate repair stone (\% of open pores) or type of mortar to avoid the establishment of new fluid circulation equilibrium or chemical interaction (Lopez-Arce et al. 2009).

\section{Materials}

Four sedimentary carbonatic lithotypes differing in fabric, commonly used as ornamental stones (Scrivano et al. 2018), were selected as test materials (Table 1). To evaluate accurately correlations between pore network characteristics, and rock weathering susceptibility to each type of saline solution, the selection was based on homogeneous mineralogy and chemical composition, and on different pore network characteristics. The selected stones are the following:

1. Breccia Aurora (BA), a polygenic breccia consisting mainly of variegated micrite fragments cemented by sparry calcite. Micro-porosity is diffuse, especially along suture veins

2. Rosso Verona (RV), a bioclastic nodular limestone (biointramicrite) whose matrix is composed predominantly of micrite and Fe-oxides. Pores occur primarily along micrite-phyllosilicate veins at the boundaries with the nodules

3. Vicenza Stone (VS), a bioclastic limestone cemented by abundant micrite matrix and in which the fossil fraction is commonly recrystallized. The pale-yellow colour of VS is due to rare oxides and hydroxides that are dispersed in the matrix. This lithotype has heterogeneous texture, with coarse- (CGV lithotype) to fine- grain size (FGV lithotype), high porosity, and diffuse micro-porosity (Scrivano et al. 2019)

BA and RV are mainly made up of compact micrite nodules or clasts cemented by veins of sparry calcite (BA), and micrite + phyllosilicate (RV). The grain size and textures control porosities and properties of the two lithotypes (Scrivano et al. 2018). Also, FGV and CGV have different grain size, resulting in different pore size distributions (Scrivano et al. 2019).

Starting from the mercury-intrusion-porosimetry (MIP) pore range distribution data already discussed in Scrivano et al. 2018 and summarized in Table 1, the Salt Susceptibility Index (SSI; Yu and Oguchi 2010) was calculated. This parameter links the pore size distribution of the lithotype with its liability to salt weathering. For SSI values lower than 4 , the lithotype is supposed to have salt weathering resistance, while for values higher than 4 the material should be subject to salt decay.

All the studied lithotypes were employed as building materials in a different part of Italy and with different functions. In particular, FGV and CGV were adopted for stairs, walls and other architectonic uses, as well as for sculpture. Under the different condition of use, weathering patterns are developed; those linked to saline solutions are mainly registered for outdoor staircases and wall basements that can suffer even severe material loss. RV and BA are primarily employed as cladding or paving in sheltered locations, however, salt induced weathering can easily become the first origin of differential erosion.

\section{Methods}

\subsection{Salt induced weathering}

The salt-induced weathering tests were carried out at the University of Zaragoza (Spain) following the continuous partial immersion procedure described by Benavente et al. (2001), using five different saturated saline solutions: $\mathrm{Na}_{2} \mathrm{SO}_{4}, \mathrm{MgSO}_{4}, \mathrm{Na}_{2} \mathrm{CO}_{3}, \mathrm{NaCl}$, and $\mathrm{KNO}_{3}$. This test alternates temperature and relative humidity cycles in a climatic chamber, to generate precipitation and dissolution from the saline solution by the wick effect. The specimens were 


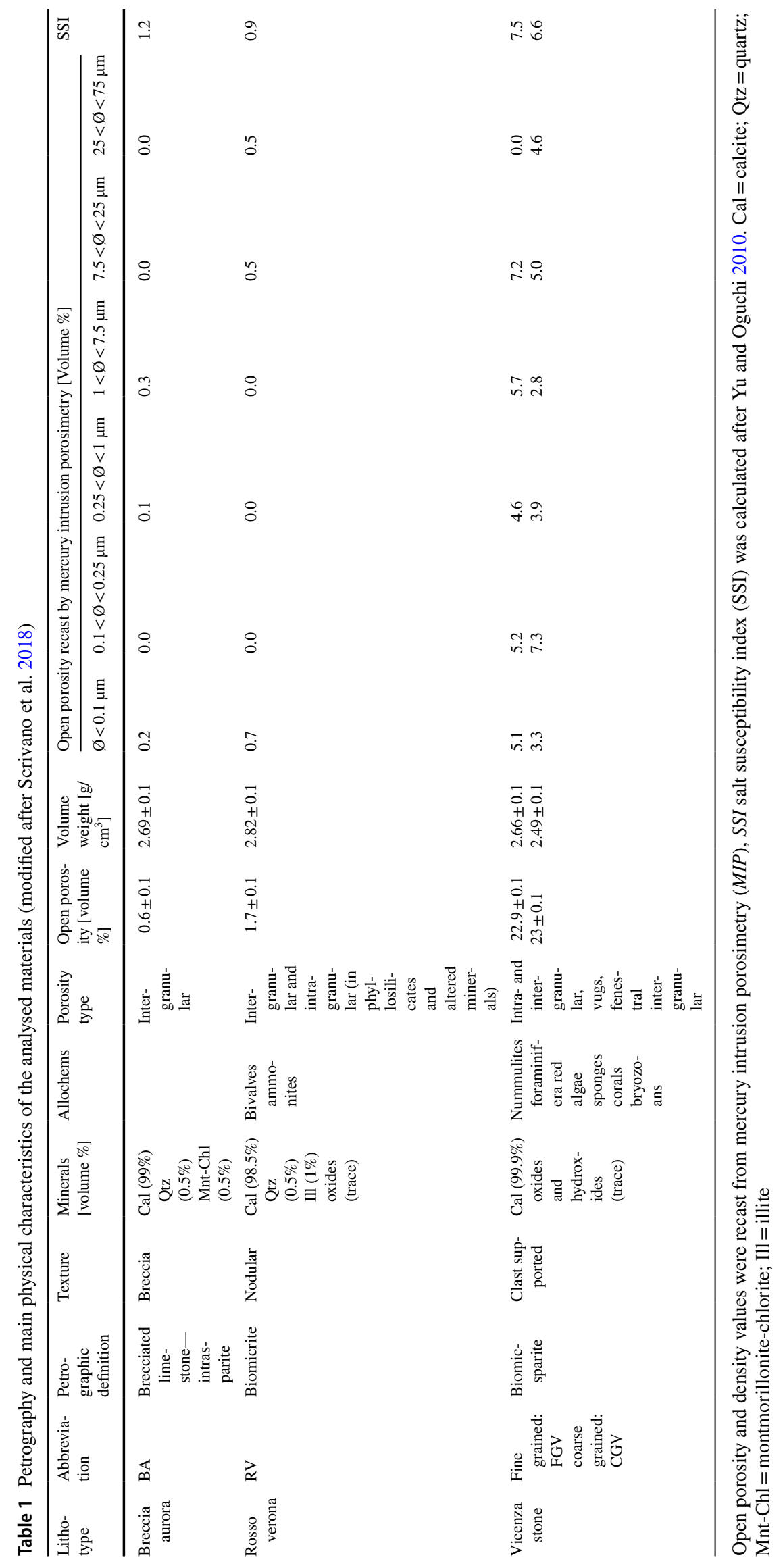


immersed to a depth of one-tenth of their height in a saturated saline solution for the complete duration of the experiment, in fact the solution level was monitored every $12 \mathrm{~h}$ to ensure that the experimental conditions were preserved. The test consisted of 15 cycles of $24 \mathrm{~h}$, in which $12 \mathrm{~h}$ were at $40{ }^{\circ} \mathrm{C}$ with $80 \% \mathrm{RH}$, then followed by $12 \mathrm{~h}$ at $30^{\circ} \mathrm{C}$ with $60 \% \mathrm{RH}$. To make sure that the solutions remained saturated, they were replaced every five cycles. Six $3 \times 3 \times 3 \mathrm{~cm}$ cubic specimens of each lithotype were tested with each salt solution (total 120 specimens). Three specimens of 6 underwent 10 treatment cycles, while the other 3 specimens underwent all 15 cycles to estimate the further evolution of the decay process. After visual inspection, and before petrophysical characterization, the specimens were rinsed with deionized water until they stopped forming efflorescence at the surfaces while drying. The process removed the salts from the porous network allowing a direct study of the pore structure.

\subsection{Weathering evaluation methodologies}

\subsubsection{Visual inspection}

The visual inspection procedure is recommended (UNI EN 12,370:2001; Lubelli et al. 2018) for evaluating saline solution-induced damage. In the present study, before rinsing off the efflorescence, macro-photographs of the specimens were acquired using a Canon EOS Rebel T3 device. The images were compared with images of the unweathered specimens, to evaluate the modifications induced by the saline solutions and the morphology of the efflorescence crusts.

Visual inspections were made after each cycle. Empirical values from 0 to 3 were assigned to the specimens based on their physical appearance: $0=$ intact specimen, $1=$ very minor change (minor rounding of corners and edges) with no decay of the integrity of the specimen, $2=$ evidence of disaggregation or cracks, $3=$ specimen without cohesion.

\subsubsection{Relative mass variation}

The calculation of the percentage of relative mass loss $(\Delta \mathrm{M})$ is recommended to represent physical deterioration according to UNI EN 12,370:2001. In the present study, relative mass loss $(\Delta \mathrm{M})$ was calculated by recording the mass of the dried specimen before $\left(m_{0}\right)$ and after salt weathering and rinsing $\left(m_{\mathrm{d}}\right)$ by the following equation:

$\Delta \mathrm{M}=\left[\left(m_{\mathrm{d}}-m_{0}\right) / m_{0}\right] \times 100$

The samples before and after weathering were oven-dried at $50{ }^{\circ} \mathrm{C}$ to record the exact dry mass. According to literature (Alves et al. 2017) also the Mass Increase (MI), representing salt crystallization as sub-efflorescence and efflorescence, was recorded following Eq. 1 and considering the mass of the specimens dried before rinsing as $\mathrm{m}_{\mathrm{d}}$.

\subsubsection{Scanning electron microscopy}

Scanning Electron Microscope (SEM) images of the surface of 20 salt-contaminated specimens (specifically cut $1 \mathrm{~cm} \times 1 \mathrm{~cm} \times 2 \mathrm{~cm}$ parallelepipeds, see Table 2) were obtained with a Tescan Vega 3 LMU SEM coupled with a microanalysis TEAM energy dispersive system (EDS) at the Department of Earth, Environment, and Life Sciences (DISTAV), University of Genoa, Italy. The specimens were mounted on aluminium stubs by carbon tape and then coated with gold sputter. SEM photomicrographs were taken under high-vacuum conditions at $200 \times, 500 \times$, and $1000 \times$ magnifications by a backscattered electron signal.

\subsubsection{Hygroscopic properties}

The hygroscopic properties of the samples, before weathering and after the salt removal from the pore network by repeated rinsing, were tested using the method specified in ISO 12,571:2013. The testing was carried out at the University of Zaragoza on 120 specimens using a climatic chamber set to maintain a temperature of $21^{\circ} \mathrm{C}$ at varying relative humidity (see Table 2 ). The relative humidity was stepwise varied at $25 \%, 50 \%, 75 \%, 90 \%$, and $95 \%$. Once the specimens reached the equilibrium for each humidity step (c. $24 \mathrm{~h}$ ), the mass of absorbed water was determined. The porosimetric curve of pores smaller than $0.1 \mu \mathrm{m}$ was calculated by correlating the relative humidity and the capillary radius, expressed by Kelvin Eq. (2)

$\varphi=\exp \left[-\frac{2 \sigma \cos \theta}{r \rho_{w} R_{D} T}\right]$

where $\varphi$ is the relative humidity value; $\sigma$ is the surface tension of water; $\theta$ is the wetting angle; $r$ is the capillary radius; $R_{\mathrm{D}}$ is the water vapour constant; $\mathrm{T}$ is the absolute temperature; and $\rho_{\mathrm{w}}$ is the water density at $\mathrm{T}$.

\subsubsection{Capillary uptake}

The UNI EN 15,801:2010 test procedure was followed to measure the capillary uptake. The oven-dried cubic specimens were placed onto a water saturated bedding layer and were weighed at determined time intervals, whose frequency depends on the pore network characteristics of the addressed lithotype. The test was stopped when the weight difference between two consecutive measurements was below $1 \%$ of the whole specimen mass. The mass data were acquired using a precision balance (accuracy $=0.01 \mathrm{~g}$ ), and the absorbed 
water per unit area $\left(Q_{\mathrm{i}}\right)$ at each time lapse was calculated using:

$Q_{\mathrm{i}}=\left[\left(m_{\mathrm{i}}-m_{\mathrm{d}}\right) / A\right]$

where $m_{\mathrm{i}}$ is the mass of the sample at each time interval, $m_{\mathrm{d}}$ is the mass of the dried sample, and A is the area of the face in direct contact with the bedding layer. A relationship was established between $Q_{\mathrm{i}}$ and time.

The specimen set is made of six $3 \mathrm{~cm} \times 3 \mathrm{~cm} \times 3 \mathrm{~cm}$ cubic samples, for each lithotype and saline solution, i.e., 240 capillary measurements were carried out before and after salt weathering on 120 total specimens (see Table 2).

\section{Results}

\subsection{Visual inspection}

The visual analysis of the weathered specimens before rinsing (Fig. 1; Table 3) shows that $\mathrm{Na}_{2} \mathrm{SO}_{4}$ and $\mathrm{Na}_{2} \mathrm{CO}_{3}$ are the most weathering-effective saline solutions among those analysed. Sample deformation observed after $\mathrm{Na}_{2} \mathrm{SO}_{4}$ and $\mathrm{Na}_{2} \mathrm{CO}_{3}$ contamination (i.e., powdering and breakage of the specimens) suggest respectively dissolution processes for FGV and CGV and swelling of the micrite-phyllosilicate veins in $\mathrm{RV}$. The $\mathrm{MgSO}_{4}$ solution caused minor rounding in FGV and CGV, and moderate swelling of the veins in $\mathrm{RV}$. The $\mathrm{NaCl}$ and $\mathrm{KNO}_{3}$ solutions affected mostly the surfaces of the specimens, producing efflorescence as fluffy and crust-like forms.

\subsection{Relative mass variations}

The relative mass loss data recorded for the different salts and lithotypes (Table 4) highlights that $\mathrm{Na}_{2} \mathrm{SO}_{4}$ and $\mathrm{Na}_{2} \mathrm{CO}_{3}$ saline solutions are exceptionally damaging to carbonates (Fig. 2). In particular, FGV and CGV underwent severe weathering, with weight loss of $c .30 \%$ after 15 cycles in the $\mathrm{Na}_{2} \mathrm{SO}_{4}$ solution, and disintegration after 15 cycles in the $\mathrm{Na}_{2} \mathrm{CO}_{3}$ solution. The weathering rate for $\mathrm{CGV}$ was higher than for FGV, resulting in higher mass variation after 10 cycles. The $\mathrm{Na}_{2} \mathrm{CO}_{3}$ saline solution caused the breakage of a part of the RV samples along the micrite + phyllosilicate joints, introducing high variability in the recorded results. The crystallization after $\mathrm{MgSO}_{4}$ solution caused a minor material loss in the more porous lithotypes (i.e., FGV and $\mathrm{CGV}$ ), whereas the compact lithotypes (i.e., RV and BA) were unaffected. The $\mathrm{NaCl}$ and $\mathrm{KNO}_{3}$ saline solutions did not cause a substantial material loss in any of the analysed materials.

Plotting the final Mass Loss (ML) against open Pore volume (P) for each specimen (Fig. 3; Alves et al. 2017)

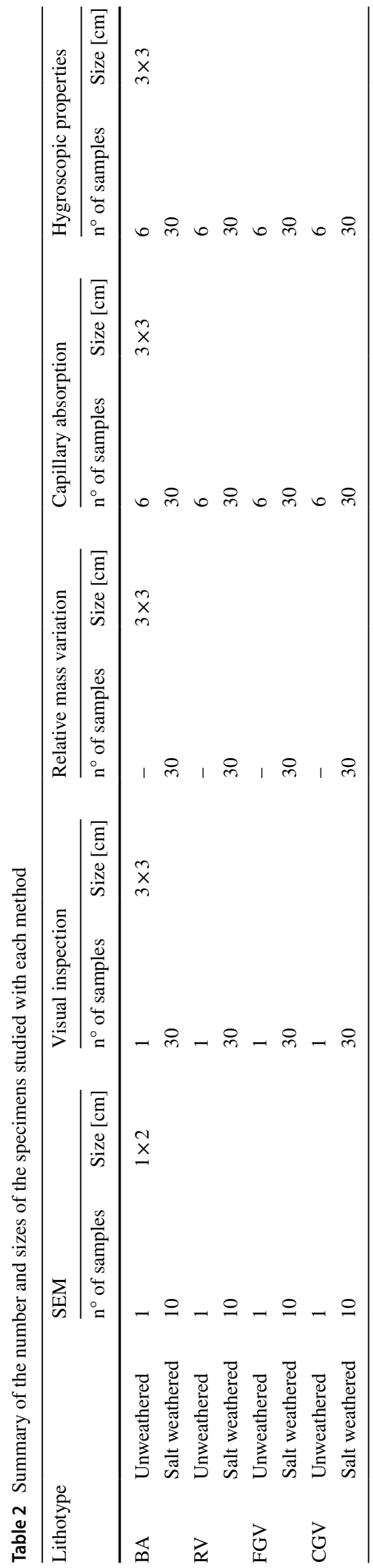




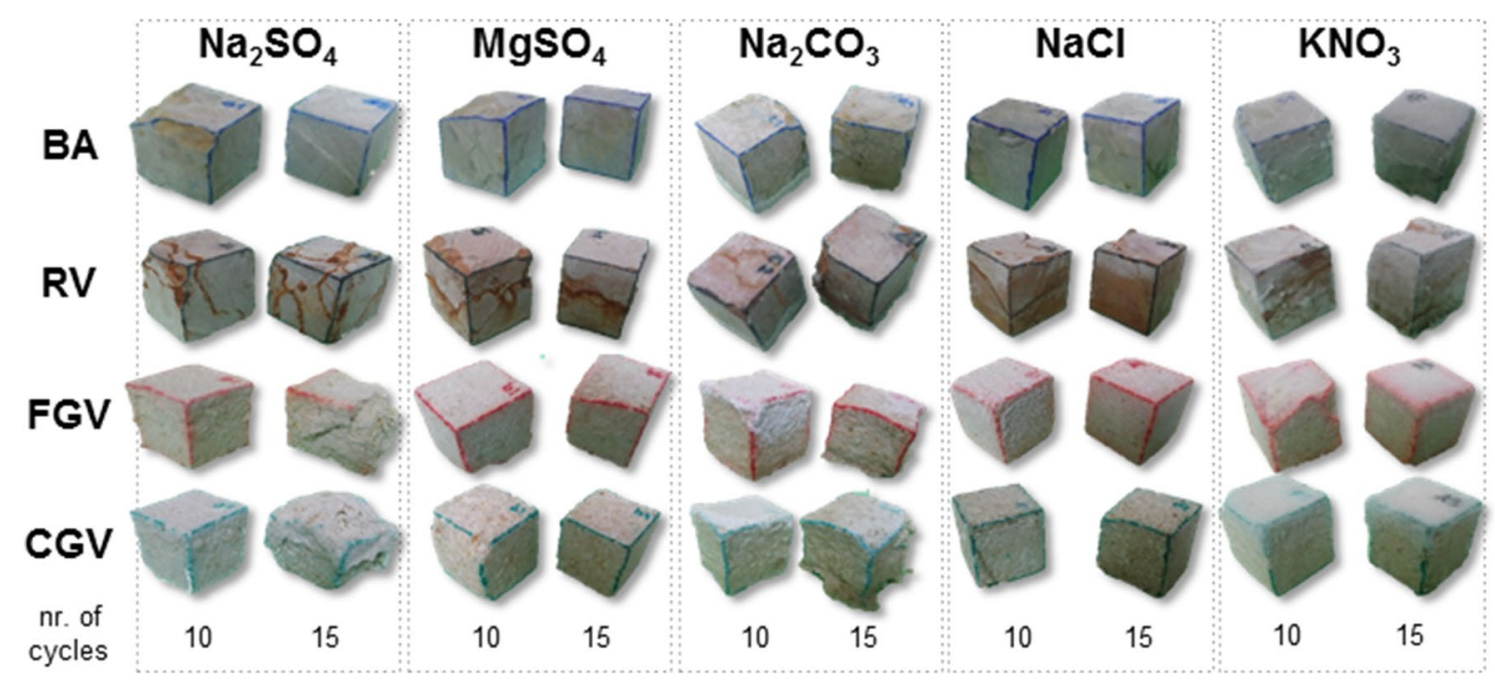

Fig. 1 Visual inspection. Photographs of the most significant specimens for each lithotype, saline solution, and time of exposure. FGV and CGV treated with $\mathrm{Na}_{2} \mathrm{SO} 4$ and $\mathrm{Na}_{2} \mathrm{CO}_{3}$ solutions show signs of deformation by deliquescence. $\mathrm{RV}$ micrite + phyllosilicate veins are

evidences that VS specimens usually have a higher mass loss, while despite having comparable open Pore volume BA and RV have different behaviours.

The ratio between MI and open Pore volume (P) (Fig. 3) shows that low porosity lithotypes (i.e., BA and RV) usually host comparable amounts of salt inside the pore network. A greater variability occurs for $\mathrm{FGV}$ and $\mathrm{CGV}$; precipitation of $\mathrm{MgSO}_{4}, \mathrm{NaCl}$ and $\mathrm{KNO}_{3}$ from the respective solutions corresponds to comparable mass increase, while $\mathrm{Na}_{2} \mathrm{SO}_{4}$ mass in percentage increases by a half, and $\mathrm{Na}_{2} \mathrm{CO}_{3}$ solution generates a double mass increase.

\subsection{Scanning electron microscopy}

The $\mathrm{Na}_{2} \mathrm{SO}_{4}$-weathered specimens have several efflorescence morphologies, ranging from a compact crust (Fig. 4a, c), to fine aggregates of anhedral microcrystals (Fig. 4b-d) and whiskers (Fig. 4b). In FGV and CGV, different efflorescence morphologies coexist (Fig. 4c). Moreover, the SEM images show that calcite is widely affected by dissolution along crystallization planes (Fig. 4d) and that stepwise precipitation of secondary calcite has occurred on the surface (Fig. 4a, c, d).

The specimens treated with the $\mathrm{MgSO}_{4}$ solution developed variably fractured salt crusts, with dissolution or dehydration pits (Fig. 4f, g). The precipitation of fine-grained saline aggregates, rarely in whiskers, is associated with major cracks across the crusts, (Fig. $4 \mathrm{f}, \mathrm{g}$ ). The $\mathrm{MgSO}_{4}$ saline solution proved aggressive, causing the dissolution of primary calcite (Fig. 4e), the formation of secondary calcite (Fig. $4 \mathrm{f})$ and tabular lamellae of gypsum $\left(\mathrm{CaSO}_{4} \cdot 2 \mathrm{H}_{2} \mathrm{O}\right.$; Fig. $4 g, h)$. more prone to decay compared with the host rock. $\mathrm{KNO}_{3}$ was crystallized on every lithotype as a thick crust on the surface of the specimens

Only BA and RV, of the four $\mathrm{Na}_{2} \mathrm{CO}_{3}$-weathered specimens, could be inspected using SEM analysis at the end of the weathering cycles because FGV and CGV were completely pulverized during the weathering experiments. At the surfaces of the specimens, the salt forms a crust with waxy texture due to thermal dissolution (Fig. 4i) and fine aggregates (Fig. 4l) with rare spherulites of radiating crystals. A secondary precipitation of calcite overprints the pristine primary texture (Fig. 4i, 1). The surface of RV shows patterns of stepwise crystallization under changing environmental conditions (Fig. 41).

The NaCl-weathered specimens have several efflorescence morphologies, ranging from a compact (Fig. 4m, n) to a composite crust composed of hollow-faced cubes (Fig. 4m), whiskers (Fig. 4n), euhedral crystals (Fig. 4o), and skeletal crystals (Fig. 4o, p). No evidence of secondary precipitation of calcite was found at the surface of the specimens.

The $\mathrm{KNO}_{3}$ solution formed a compact salt crust with rare filaments; moreover dissolution features of the carbonatic substrate were observed (Fig. 4s, t). Notably, the onset of

Table 3 Visual inspection after 15 cycles. Empirical ranking from 0 to 3 , assigned to the different appearances of the materials after weathering: $0=$ intact, $1=$ minor change with no decay of the integrity of the specimen, $2=$ disaggregation or cracks, $3=$ no resistance

\begin{tabular}{llllll}
\hline & $\mathrm{Na}_{2} \mathrm{SO}_{4}$ & $\mathrm{MgSO}_{4}$ & $\mathrm{Na}_{2} \mathrm{CO}_{3}$ & $\mathrm{NaCl}$ & $\mathrm{KNO}_{3}$ \\
\hline $\mathrm{BA}$ & 0 & 0 & 0 & 0 & 0 \\
$\mathrm{RV}$ & 1 & 1 & 2 & 0 & 0 \\
$\mathrm{FGV}$ & 3 & 1 & 3 & 0 & 0 \\
$\mathrm{CGV}$ & 3 & 1 & 3 & 0 & 0 \\
\hline
\end{tabular}


Table 4 Summary of relative mass variation data, microporosity increase-decrease and SSI adequacy

\begin{tabular}{|c|c|c|c|c|c|c|c|}
\hline Lithotype & Salt & $\begin{array}{l}\text { MI after } 10 \\
\text { cycles [\% i.w.] }\end{array}$ & $\begin{array}{l}\text { MI after } 15 \\
\text { cycles [\% i.w.] }\end{array}$ & $\begin{array}{l}\text { ML after } 10 \\
\text { cycles [\% i.w.] }\end{array}$ & $\begin{array}{l}\text { ML after } 15 \\
\text { cycles [\% i.w.] }\end{array}$ & $\begin{array}{l}\text { Increase in micropores } \\
\text { [\% total volume] }\end{array}$ & Adequacy of SSI \\
\hline \multirow[t]{5}{*}{$\mathrm{BA}$} & $\mathrm{Na}_{2} \mathrm{SO}_{4}$ & $-0.1 \pm 0.2$ & $0.1 \pm 0.1$ & $0.04 \pm 0.01$ & $0.07 \pm 0.05$ & $0.06 \pm 0.01$ & ++ \\
\hline & $\mathrm{MgSO}_{4}$ & $0.15 \pm 0.04$ & $0.52 \pm 0.06$ & $0.03 \pm 0.02$ & $0.02 \pm 0.07$ & $-0.001 \pm 0.001$ & ++ \\
\hline & $\mathrm{Na}_{2} \mathrm{CO}_{3}$ & $0.16 \pm 0.02$ & $0.5 \pm 2.05$ & $0.03 \pm 0.03$ & $0.08 \pm 0.01$ & $0.07 \pm 0.01$ & ++ \\
\hline & $\mathrm{NaCl}$ & $0.2 \pm 0.03$ & $0.28 \pm 0.03$ & $0.01 \pm 0.02$ & $0.03 \pm 0.02$ & $0.22 \pm 0.1$ & ++ \\
\hline & $\mathrm{KNO}_{3}$ & $0.87 \pm 0.67$ & $1.64 \pm 0.5$ & $0.001 \pm 0.001$ & $0.01 \pm 0.01$ & $0.1 \pm 0.01$ & ++ \\
\hline \multirow[t]{5}{*}{ RV } & $\mathrm{Na}_{2} \mathrm{SO}_{4}$ & $0.1 \pm 0.0$ & $0.6 \pm 0.4$ & $0.15 \pm 0.05$ & $2.11 \pm 0.6$ & $0.76 \pm 0.2$ & + \\
\hline & $\mathrm{MgSO}_{4}$ & $0.44 \pm 0.4$ & $0.88 \pm 0.28$ & $0.14 \pm 0.6$ & $0.33 \pm 0.5$ & $0.34 \pm 0.1$ & ++ \\
\hline & $\mathrm{Na}_{2} \mathrm{CO}_{3}$ & $0.37 \pm 1.22$ & $2.58 \pm 4.45$ & $33.95 \pm 57.21$ & $33.5 \pm 57.6$ & $-0.16 \pm 0.1$ & - \\
\hline & $\mathrm{NaCl}$ & $0.54 \pm 0.08$ & $0.61 \pm 0.01$ & $0.17 \pm 0.09$ & $0.09 \pm 0.03$ & $0.3 \pm 0.1$ & ++ \\
\hline & $\mathrm{KNO}_{3}$ & $0.78 \pm 0.7$ & $1.37 \pm 0.12$ & $0.13 \pm 0.04$ & $0.17 \pm 0.09$ & $0.27 \pm 0.1$ & ++ \\
\hline \multirow[t]{5}{*}{ FGV } & $\mathrm{Na}_{2} \mathrm{SO}_{4}$ & $6.0 \pm 7.1$ & $2.3 \pm 6.7$ & $15.65 \pm 4.63$ & $34.01 \pm 12.2$ & $1.9 \pm 0.1$ & ++ \\
\hline & $\mathrm{MgSO}_{4}$ & $9.45 \pm 0.53$ & $15.61 \pm 0.39$ & $2.08 \pm 1.29$ & $1.43 \pm 0.92$ & $5.26 \pm 0.2$ & + \\
\hline & $\mathrm{Na}_{2} \mathrm{CO}_{3}$ & $17.3 \pm 4.28$ & $32.91 \pm 3.68$ & $46.72 \pm 46.3$ & $100 \pm \mathrm{n} . \mathrm{d}$ & $5.71 \pm 0.1$ & ++ \\
\hline & $\mathrm{NaCl}$ & $10.15 \pm 0.8$ & $13.38 \pm 0.56$ & $0.17 \pm 0.02$ & $0.12 \pm 0.07$ & $3.33 \pm 0.2$ & - \\
\hline & $\mathrm{KNO}_{3}$ & $12.22 \pm 0.7$ & $14.33 \pm 7.21$ & $0.25 \pm 0.07$ & $0.19 \pm 0.04$ & $3.24 \pm 0.2$ & - \\
\hline \multirow[t]{5}{*}{ CGV } & $\mathrm{Na}_{2} \mathrm{SO}_{4}$ & $3.8 \pm 3.6$ & $7.8 \pm 1.1$ & $25.46 \pm 13.24$ & $27.97 \pm 8.51$ & $1.9 \pm 0.1$ & ++ \\
\hline & $\mathrm{MgSO}_{4}$ & $9.37 \pm 0.83$ & $14.83 \pm 0.35$ & $2.33 \pm 1.29$ & $2.18 \pm 0.6$ & $5.56 \pm 0.1$ & + \\
\hline & $\mathrm{Na}_{2} \mathrm{CO}_{3}$ & $18.84 \pm 4.39$ & $30.15 \pm 6.61$ & $72.98 \pm 46.8$ & $100 \pm \mathrm{n} . \mathrm{d}$ & $7.78 \pm 0.2$ & ++ \\
\hline & $\mathrm{NaCl}$ & $9.77 \pm 0.78$ & $13.25 \pm 0.99$ & $0.2 \pm 0.09$ & $0.18 \pm 0.01$ & $3.53 \pm 0.1$ & - \\
\hline & $\mathrm{KNO}_{3}$ & $11.41 \pm 1.67$ & $15.16 \pm 0.93$ & $0.17 \pm 0.15$ & $0.16 \pm 0.07$ & $3.46 \pm 0.2$ & - \\
\hline
\end{tabular}

Mass Increase (MI) and Mass Loss (ML) for 10 and 15 cycles are reported with their standard deviation. For SSI adequacy: $++=$ very adequate $;=$ adequate $;-=$ inadequate

crystal nucleation occurred along the cleavages of calcite crystal (Fig. 4q), and secondary calcite developed on the earlier crust (Fig. 4r).

\subsection{Hygroscopic properties}

Hygroscopic-based porosimetry of the unweathered and of 15 cycles-weathered specimens (for all the samples except for FGV and $\mathrm{CGV}$ in $\mathrm{Na}_{2} \mathrm{CO}_{3}$ solution, whose data are referred to the samples at 10 cycles), allowed identifying changes in micro-pore distribution (Fig. 5). In RV, FGV, and $\mathrm{CGV}$ in $\mathrm{Na}_{2} \mathrm{SO}_{4}$-treated specimens, a class of pores smaller than $0.002 \mu \mathrm{m}$ developed, along with an increase in the frequency of pores measuring $0.003-0.1 \mu \mathrm{m}$. In FGV and CGV, a significant increase in the number of pores with $c .0 .1 \mathrm{~mm}$ diameter occurred. A similar modification of the pore network was also observed in $\mathrm{MgSO}_{4}$-treated specimens. In FGV and $\mathrm{CGV}, \mathrm{NaCl}$ and $\mathrm{KNO}_{3}$ induced modifications in the distribution of micro-pores. Finally, BA specimens were not affected by any of the tested solutions.

\subsection{Capillary uptake}

The capillary uptake was measured before and after the weathering test with different saline solutions for all
specimens(Fig. 6). In particular, after $c .45 \mathrm{~h}$ (Fig. 6, left side) the weathered specimens absorbed less water than the unweathered ones, except for $\mathrm{BA}$ and $\mathrm{RV}$ after $\mathrm{NaCl}$ and $\mathrm{KNO}_{3}$ contamination. Conversely, in the first two minutes of the test (Fig. 6 right side), the water content for the weathered samples shows a faster increase. The BA specimens show a slight decrease in the velocity of capillary rise when exposed to the $\mathrm{Na}_{2} \mathrm{CO}_{3}$ and $\mathrm{MgSO}_{4}$ solutions, whereas an increase in velocity occurred in the $\mathrm{Na}_{2} \mathrm{SO}_{4^{-}}, \mathrm{NaCl}-$ and $\mathrm{KNO}_{3}$-weathered specimens. The capillary dataset for $\mathrm{RV}$ showed a slight decrease in the velocity of water absorption for all weathered specimens. The FGV and CGV lithotypes are affected by an increase in capillary absorption rates for all specimens.

\section{Discussion}

The precipitation of salt crystals occurred inside and outside the pore network, depending on the physical features of the pore network or on the solutions. Precipitation is associated inside the stone with modification of petrophysical parameters, and outside with evidence of salt crusts at the macroscale. Following salt precipitation, also deterioration by cracks, efflorescence and sub-efflorescence, 

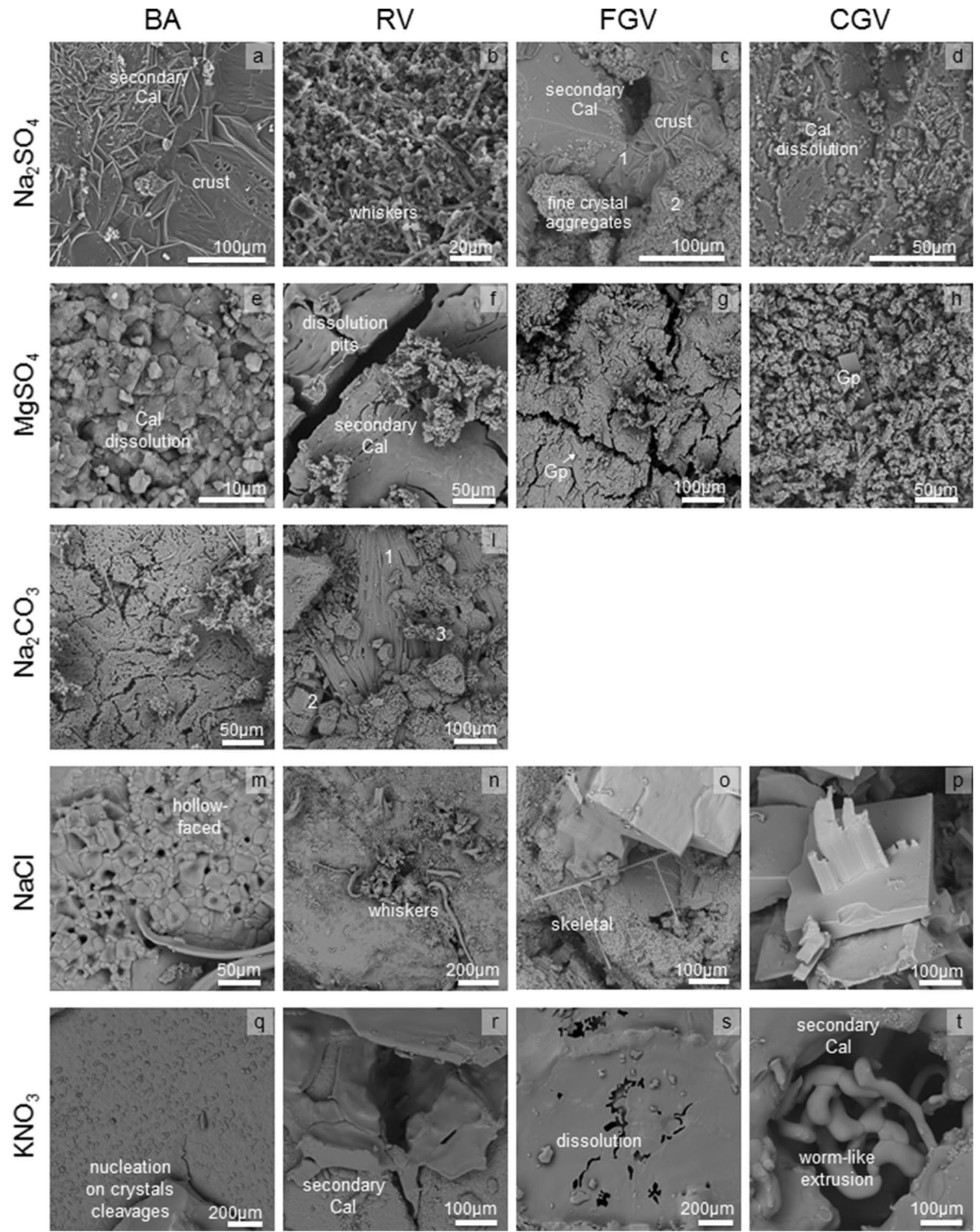

Fig. 2 Relative mass variation. The diagrams show the mass variation relative to the initial mass (in percent) for each saline solution. The different colours correspond to different lithotypes: gray $=\mathrm{BA}$; orange $=\mathrm{RV}$; green $=\mathrm{FGV}$; purple $=\mathrm{CGV}$. The data are averaged for the set with 10 cycles of weathering (triangles + dashed lines) and for the set with 15 cycles of weathering (squares + solid lines). Salts $=$ dry mass of the samples with salts, water $=$ mass of the wet samples after rinsing, dry $=$ dry mass of the samples after rinsing 
Fig. 3 Relative mass variations. Top: Plot of final mass loss (ML) against maximum mass increase (MI) expressed as \% of the total volume. Bottom: Plot of mass increase (MI) in [g], against pore volume (P) in $\left[\mathrm{cm}^{3}\right]$. Circle $=\mathrm{BA}$; square $=\mathrm{RV}$; triangle $=\mathrm{FGV}$ and rhombohedra $=\mathrm{CGV}$

chemical reactions, grain loss, and rounding developed. Cracks develop in the RV samples mainly along the micrite + phyllosilicate veins. This texture, characterized by higher porosity than the nodules and by highly reactive surface, due to the fine calcite diameter, is the weakest element of the lithotype.

Grain loss and rounding characterize mainly the two bioclastic VS limestones. Efflorescence, sub-efflorescence and chemical reactions affect at different extent all the lithotypes. The chosen solution are generally weakly acidic, fact that explains the patterns of secondary precipitation in every sample. Conversely, $\mathrm{Na}_{2} \mathrm{CO}_{3}$ having $\mathrm{pH}$ around 10 , have a basic behaviour, more effective in dissolving mineral phases.

Under SEM, several distinct efflorescence morphologies for the different saline species were revealed. Herein, some of the saline solutions, under alternating hydration-dehydration, and variable temperature-humidity rate during the testing procedure, allowed crystals to precipitate and subsequently modify. Furthermore, the diverse patterns of crystallization depend on the environmental conditions: euhedral crystals or compact crusts represent precipitation from solution in a damp environment, whereas skeletal forms and cracks appear to be the most diffuse crystallization habits developed during evaporation (Rodriguez-Navarro et al. 2000; Charola et al. 2007, 2017; Lopez-Arce et al. 2009; Lubelli et al. 2018). The development of overlapping series of different morphologies can be interpreted as signs of a stepwise crystallization influenced by the environmental conditions.

The most porous lithotypes, FGV and CGV, presented the highest SSI values and, in fact, were the most liable to material loss and modification of their hydric properties. In particular, the stones showed high weathering rates when exposed to $\mathrm{Na}_{2} \mathrm{SO}_{4}, \mathrm{Na}_{2} \mathrm{CO}_{3}$, and $\mathrm{MgSO}_{4}$ solutions. The modification of the micro-pore network, i.e. increase in capillary rise during the first minutes of soaking, and hygroscopic sorption variations, took place during exposure to all saline solution, and was confirmed by relative mass variation (Table 4). Moreover, as the complete capillary absorption dataset includes a decrease of the total content of water absorbed by the specimens, the widening of the larger pores, can be inferred as related with mechanical stresses and calcite dissolution. The latter is assumed after the observation of secondary calcite re-precipitation for all the saline solutions. Moreover, the formation of tabular crystals of calcium sulphate, probably gypsum, on the specimens treated with

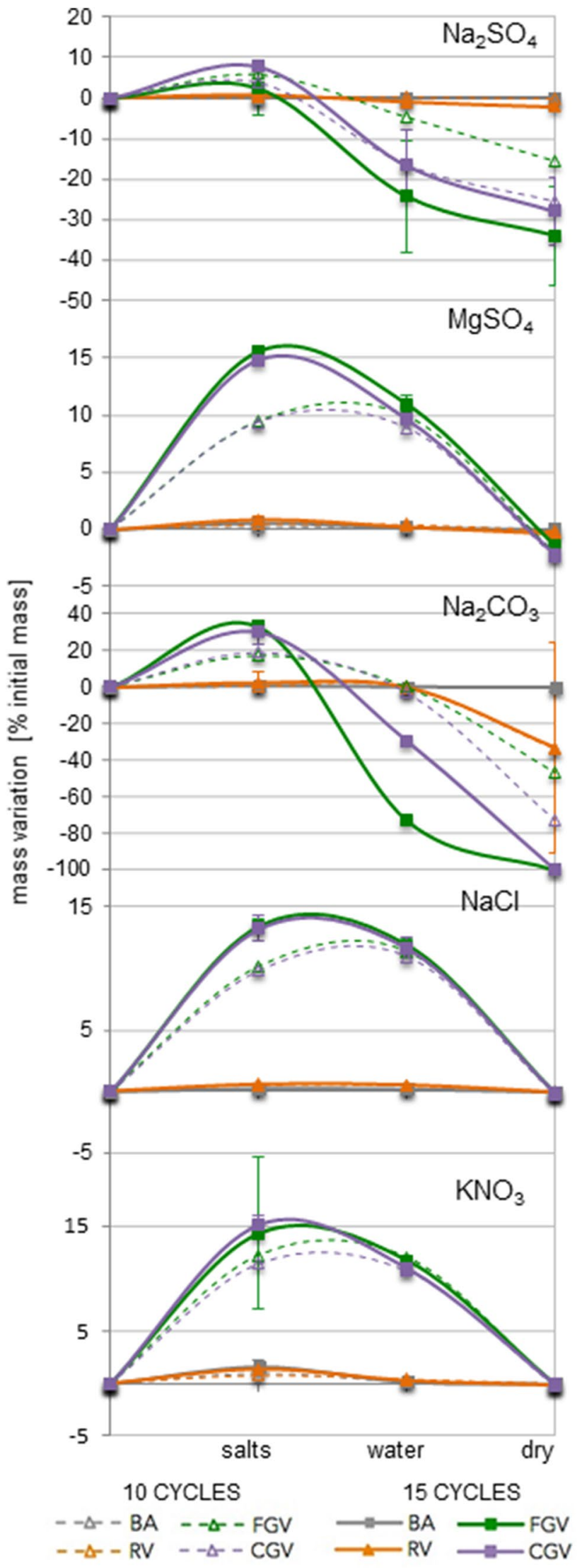




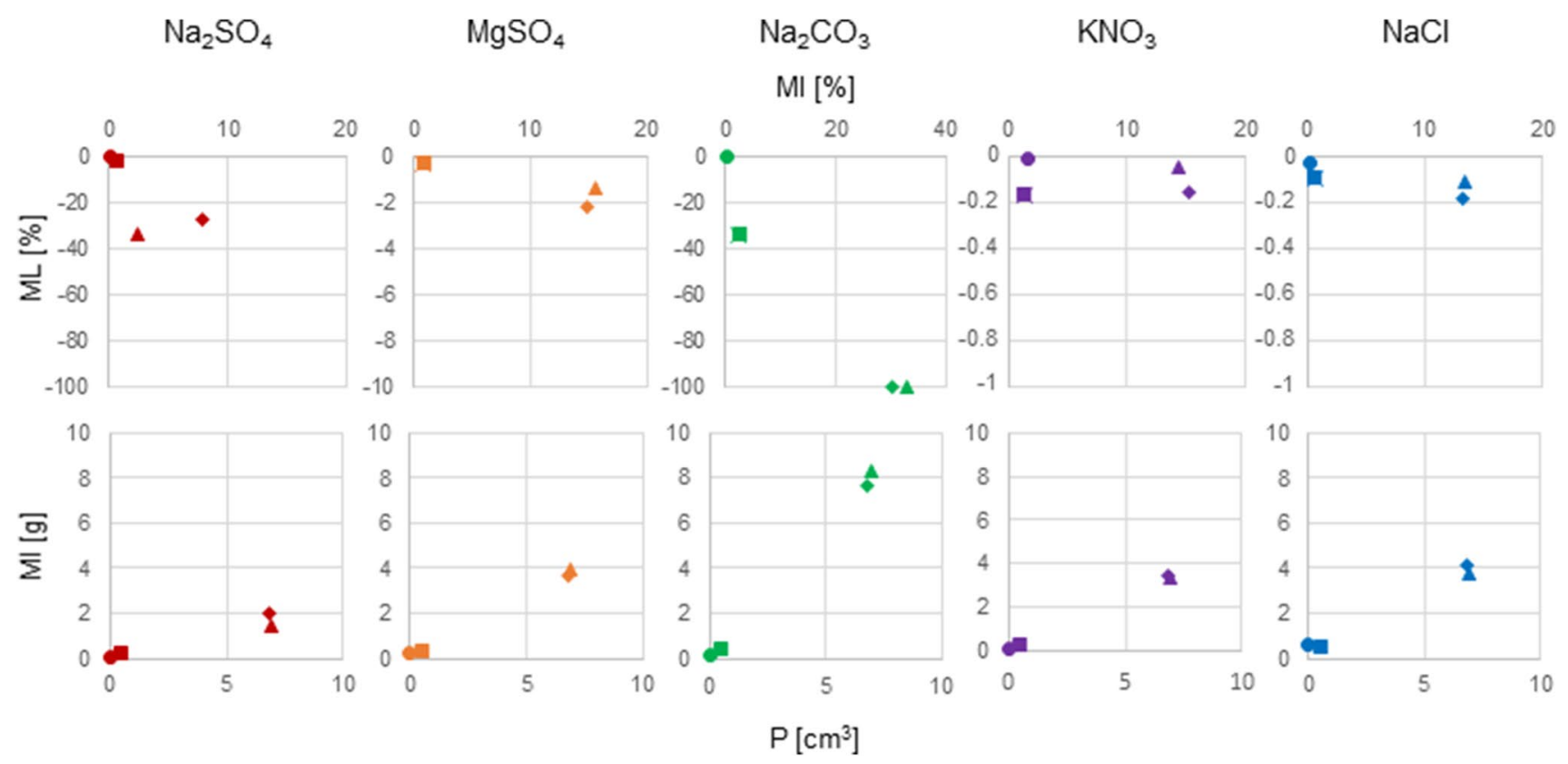

Fig. 4 SEM photomicrographs (various magnifications) at the surfaces of the control specimens for each lithotype and saline solution tested. Different crystallization shapes and phases are focussed

sulphate solutions confirms that chemical reactions occurred at the rock surface.

Despite its low SSI parameter, RV was affected by $\mathrm{Na}_{2} \mathrm{SO}_{4}$ and $\mathrm{Na}_{2} \mathrm{CO}_{3}$ solutions. Visual inspection and SEM images showed that the most conspicuous crystallization occurred at the micrite-phyllosilicates veins, sparing the compact nodules, with consequent differential behaviour between the two zones with diverse porosity (Benavente et al. 2007). The differential durability of nodules and veins place this lithotype in the category of dual-porosity materials. Therefore, the SSI value rather reflects the hardness of the nodules, whereas the veins are more weatherable. In RV the pore network within the micrite-phyllosilicates veins was modified by pore enlargement (Scrivano et al. 2018) especially after $\mathrm{Na}_{2} \mathrm{SO}_{4}, \mathrm{MgSO}_{4}$ and $\mathrm{Na}_{2} \mathrm{CO}_{3}$ salt contamination. The joints interested by the mechanical and chemical stresses induced by the saline solutions explains the small rate of decay, compared to CGV and FGV.

The compactness of BA resulted in high resistance to salt decay, as demonstrated by the slight modification of hydric properties and the virtual lack of mass loss, consistent with the values of SSI.

The main difference in the behaviour of RV and BA resides in the veins. In fact, while the recrystallized veins of BA are as compact as the breccia clasts, the micrite + phyllosilicates joints cementing the micritic nodules of RV are characterized by diffuse inter-granular + intra-granular pores resulting in a widespread reactive surface. Moreover, the different behaviour of nodules and veins in the lithotype led to differential weathering and breaking, especially in $\mathrm{RV}+\mathrm{Na}_{2} \mathrm{CO}_{3}$.

Overall, the SSI proved efficient in predicting the behaviour of homogenous lithotypes (i.e. BA, FGV and CGV), however, this index does not consider the chemical activity of the different saline solutions, thus overrating the susceptibility of FGV and CGV to $\mathrm{MgSO}_{4}, \mathrm{NaCl}$ and $\mathrm{KNO}_{3}$.

Generally, the most compact fabric (BA and RV nodules) account for a greater durability to salt action, while high open porosity values (FGV and CGV) and abundance of micrite (RV) caused higher susceptibility to decay; in particular, FGV, CGV and RV micrite + phyllosilicate veins showed low durability for sulphate and carbonate contamination. Therefore, caution must be adopted when using these stones in outdoor for the presence of acid rains, and in the presence of lime-based bedding mortars and high capillaryrise rate.

\section{Conclusions}

The experiments on the four carbonatic sedimentary stones allow the following conclusions:

1. The rocks with the more compact textures (BA) are less susceptible to decay compared with the more porous (FGV, CGV) or more heterogeneous structures (RV), suggesting a link between a higher specific reactive surface and higher weathering susceptibility 

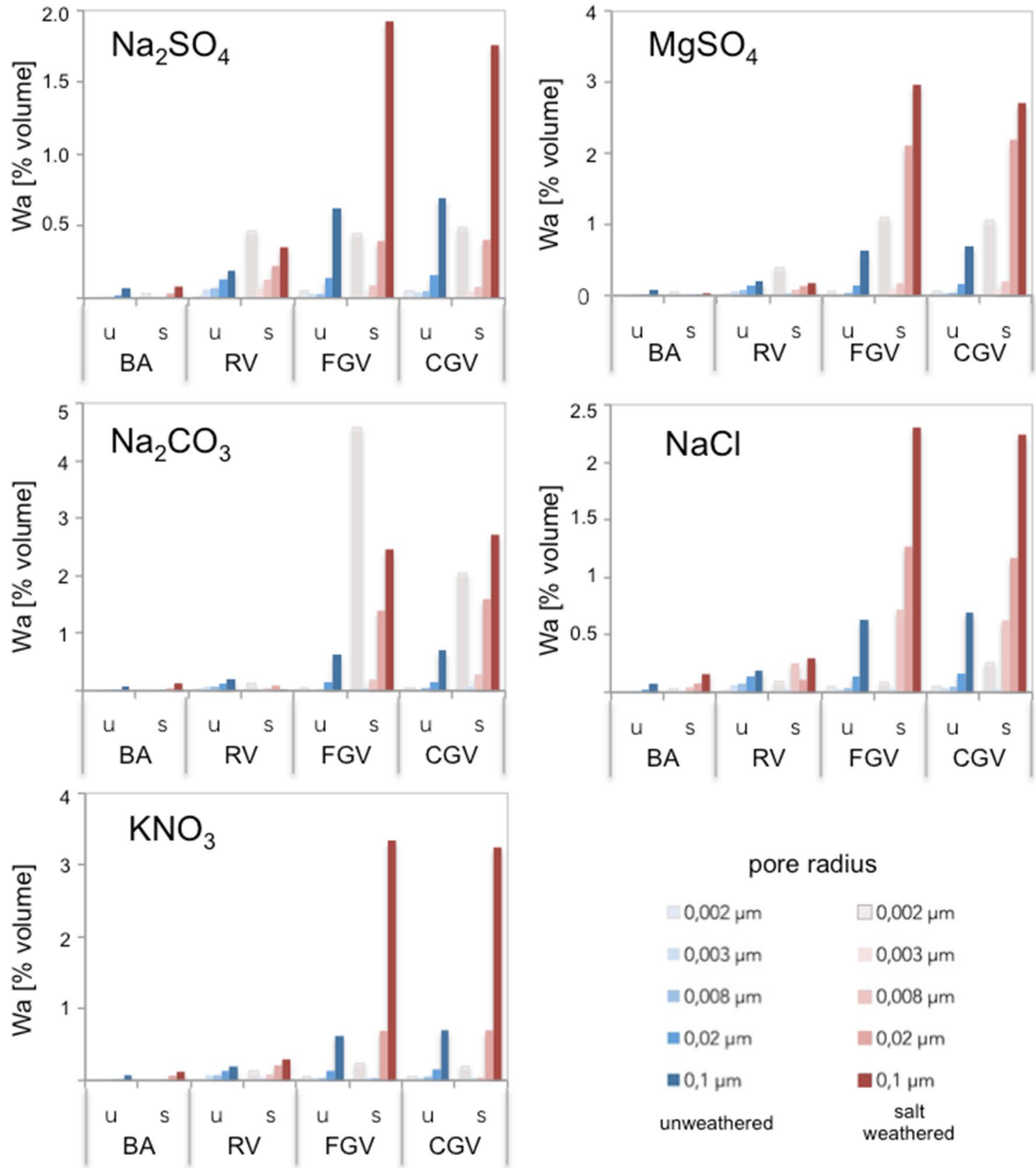

pore radius

$\begin{array}{lc}\square, 002 \mu \mathrm{m} & \square 0,002 \mu \mathrm{m} \\ \square 0,003 \mu \mathrm{m} & 0,003 \mu \mathrm{m} \\ \varpi 0,008 \mu \mathrm{m} & \square 0,008 \mu \mathrm{m} \\ \varpi 0,02 \mu \mathrm{m} & \square 0,02 \mu \mathrm{m} \\ \square 0,1 \mu \mathrm{m} & \square 0,1 \mu \mathrm{m} \\ & \text { salt } \\ \text { unweathered } & \text { weathered }\end{array}$

Fig. 5 Hygroscopic-sorption-based porosimetry. Bar diagrams showing the calculated micro-pore distribution for each lithotype and saline solution before (u, blue bars) and after (s, red bars) weathering. FGV and CGV show wide variations in the micro-porosimetric distribution profile

2. The use of different saline solutions enabled determining the impact of each salt on the stone. $\mathrm{Na}_{2} \mathrm{SO}_{4}$ and $\mathrm{Na}_{2} \mathrm{CO}_{3}$ were found to induce the highest weathering rates in the tested materials due to their chemical interaction with the rocks and the liability to crystallize under different hydration states
3. The SEM-EDS microanalysis revealed that sulphates interact chemically with the carbonate substrate, forming secondary minerals (mainly gypsum)

4. The hydric test methods were effective for recording porosimetric variation; in particular, capillary absorption assessed the enlargement of capillary pores during the weathering process 
Fig. 6 Capillary absorption. A comparison of mean values representing unweathered (black lines) and saltweathered $\left(\mathrm{Na}_{2} \mathrm{SO}_{4}=\right.$ red; $\mathrm{MgSO}_{4}=$ orange;

$\mathrm{Na}_{2} \mathrm{CO}_{3}=$ green; $\mathrm{NaCl}=$ blue; $\mathrm{KNO}_{3}=$ purple) specimens. The variations in the pore networks are highlighted by the different profiles of the Qi vs. $\sqrt{ }$ T curves

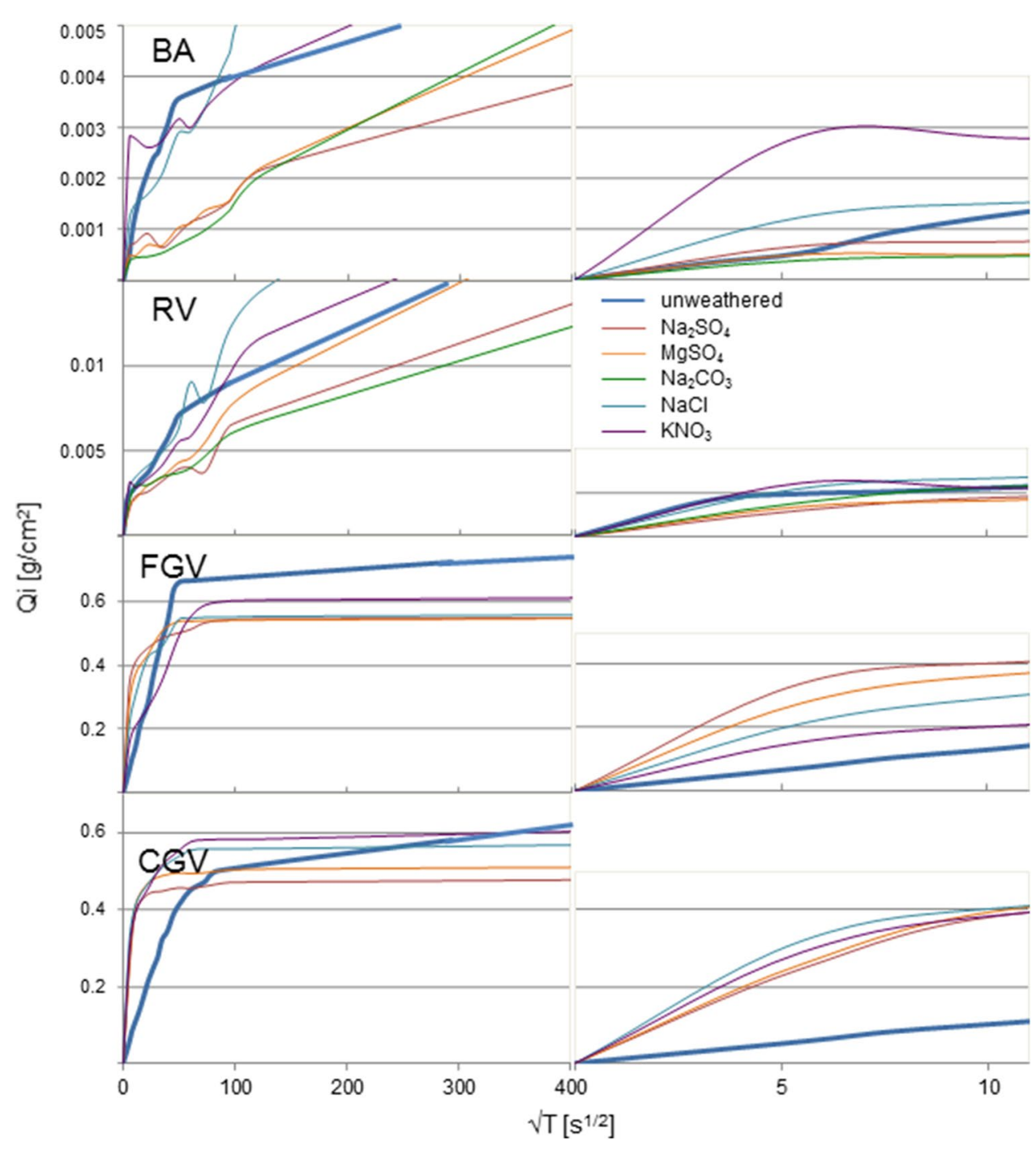

5. The SSI proved not completely reliable because it does not take into account the properties of the different saline solutions, and their chemical interaction with the host rock. Moreover, SSI depends on porosimetric distribution calculations that are possibly affected by textural or compositional inhomogeneities of the addressed lithotypes

6. The susceptibility to salt decay of RV, FGV, and CGV advises against their use in outdoor for new constructions and suggests cautions when dealing with dimension stone blocks used in historical structures

Acknowledgements We acknowledge the careful revision of two anonymous referees, who helped improving the manuscript. We acknowledge the financial support of the "Analisi delle proprietà microstrutturali, chimico-fisiche di materiali inorganici; determinazioni quantitative della composizione mineralogica di materiali naturali e delle proprietà tecniche dei materiali litici” Laboratory funds, DISTAV, University of Genoa. The authors thank Prof. Josep Gisbert Aguilar of the University of Zaragoza (ES) for the help in the weathering test structuring; Adrian Yus Gonzalez for his support in SEM-EDS analyses; Breccia Aurora s.r.l, Fasani Celeste s.r.l., and Nichele Fratelli s.r.l. for providing the samples.

Funding Open access funding provided by Universit Ã degli Studi di Genova within the CRUI-CARE Agreement.

\section{Compliance with ethical standards}

Conflict of interest The authors declare that they have no conflict of interest.

Open Access This article is licensed under a Creative Commons Attribution 4.0 International License, which permits use, sharing, adaptation, distribution and reproduction in any medium or format, as long 
as you give appropriate credit to the original author(s) and the source, provide a link to the Creative Commons licence, and indicate if changes were made. The images or other third party material in this article are included in the article's Creative Commons licence, unless indicated otherwise in a credit line to the material. If material is not included in the article's Creative Commons licence and your intended use is not permitted by statutory regulation or exceeds the permitted use, you will need to obtain permission directly from the copyright holder. To view a copy of this licence, visit http://creativecommons.org/licenses/by/4.0/.

\section{References}

Akin M, Özsan A (2011) Evaluation of the long-term durability of yellow travertine using accelerated weathering tests. Bull Eng Geol Environ 70:101-114. https://doi.org/10.1007/s10064-010-0287-x

Alonso FJ, Vázquez P, Esbert RM, Ordaz J (2008) Ornamental granite durability: evaluation of damage caused by salt crystallization test. Mater Constr 58:191-202

Alves C, Figueiredo C, Maurício A et al (2017) Weathering hazards. Bull Eng Geol Environ 76:377-390. https://doi.org/10.1144/qjegh 2012-052

Amoroso GG, Fassina V (1983) Stone decay and conservation. Elsevier Science Publisher, Amsterdam

Angeli M, Benavente D, Bigas JP et al (2008) Modification of the porous network by salt crystallization in experimentally weathered sedimentary stones. Mater Struct Constr 41:1091-1108. https:// doi.org/10.1617/s11527-007-9308-Z

Angeli M, Hébert R, Menéndez B et al (2010) Influence of temperature and salt concentration on the salt weathering of a sedimentary stone with sodium sulphate. Eng Geol 115:193-199. https://doi. org/10.1016/j.enggeo.2009.06.001

Arnold A (1981) Nature and reactions of saline minerals in walls: The Conservation of Stone II, Bologna, October 27-30, 1981, p. 13-23

Arnold A, Kueng A (1985) Crystallization and habits of salt efflorescences on walls, I, Methods of investigation and habits. In: Félix G (ed) Fifth International Congress on the Deterioration and Conservation of Stone, Presses Polytechniques Romandes, Lausanne, p. 255-267

Arnold A, Zehnder K (1990) Salt weathering on monuments. In: Zezza F (ed) The conservation of monuments in the Mediterranean Basin: the influence of coastal environment and salt spray on limestone and marble. Proceedings of the 1st International Symposium, Bari, Grafo Edizioni, Brescia, pp 31-58, 7-10 June 1989

Arnold A, Zehnder K (1991) Monitoring Wall Paintings Affected by Soluble Salts. In: The conservation of wall paintings; proceedings of a symposium organized by the Courtauld Institute of Art and the Getty Conservation Institute, London, July 13-16 1987. Getty Conservation Institute, pp. 103-135. ISBN 0-89236-162-X

Benavente D, García-Del-Cura MÁ, Fort R, Ordóñez S (2004a) Durability estimation of porous building stones from pore structure and strength. Eng Geol 74:113-127

Benavente D, García Del Cura MA, Bernabéu A, Ordóñez S (2001) Quantification of salt weathering in porous stones using an experimental continous partial immersion method. Eng Geol 59:313325. https://doi.org/10.1016/S0013-7952(01)00020-5

Benavente D, García del Cura MA, García-Guinea J et al (2004b) Role of pore structure in salt crystallisation in unsaturated porous stone. J Cryst Growth 260:532-544. https://doi.org/10.1016/j. jcrysgro.2003.09.004

Benavente D, Martínez-Martínez J, Cueto N, García-del-Cura MA (2007) Salt weathering in dual-porosity building dolostones. Eng Geol 94:215-226. https://doi.org/10.1016/j.enggeo.2007.08.003
Benavente D, Martínez-Martínez J, Jáuregui P et al (2006) Assessment of the strength of building rocks using signal processing procedures. Constr Build Mater 20:562-568

Cardell C, Benavente D, Rodríguez-Gordillo J (2008) Weathering of limestone building material by mixed sulfate solutions. Characterization of stone microstructure, reaction products and decay forms. Mater Charact 59:1371-1385. https://doi.org/10.1016/j. matchar.2007.12.003

Cardell C, Delalieux F, Roumpopoulos K et al (2003) Salt-induced decay in calcareous stone monuments and buildings in a marine environment in SW France. Constr Build Mater 17:165-179. https ://doi.org/10.1016/S0950-0618(02)00104-6

Castellazzi G, Colla C, De Miranda S et al (2013) A coupled multiphase model for hygrothermal analysis of masonry structures and prediction of stress induced by salt crystallization. Constr Build Mater 41:717-731. https://doi.org/10.1016/j.conbuildma t.2012.12.045

Çelik MY, Aygün A (2019) The effect of salt crystallization on degradation of volcanic building stones by sodium sulfates and sodium chlorides. Bull Eng Geol Environ 78:3509-3529. https://doi. org/10.1007/s10064-018-1354-y

Ceryan S, Tudes S, Ceryan N (2008) Influence of weathering on the engineering properties of Harsit granitic rocks (NE Turkey). Bull Eng Geol Environ 67:97-104

Charola AE, Pühringer J, Steiger M (2007) Gypsum: A review of its role in the deterioration of building materials. Environ Geol 52:207-220. https://doi.org/10.1007/s00254-006-0566-9

Charola A E, Rörig-Dalgaard I, Chwast J, Elsen J (2017) Salt crystallization tests: Focus on their objective. In: Paper presented at 4th International Conference on Salt Weathering of Buildings and Stone Sculptures, Potsdam, Germany

Dessandier D (2000) Durability of tuffeau stone buildings:influence of mineralogical composition and microstructural properties. In: 9th International Congress on Deterioration and Conservation of Stone. Venice, June 19-24, pp 69-78, Elsevier Science

Di Benedetto C, Cappelletti P, Favaro M et al (2015) Porosity as key factor in the durability of two historical building stones: Neapolitan Yellow Tuff and Vicenza Stone. Eng Geol 193:310-319. https ://doi.org/10.1016/j.enggeo.2015.05.006

Diaz Gonçalves T, Brito V (2014) Alteration kinetics of natural stones due to sodium sulfate crystallization: Can reality match experimental simulations? Environ Earth Sci 72:1789-1799. https://doi. org/10.1007/s12665-014-3085-0

Everett DH (1961) The thermodynamics of frost damage to porous solids. Trans Faraday Soc 57:1541-1551. https://doi.org/10.1039/ TF9615701541

Fitzner B, Snethlage R (1982) Einfluss der porenradien verteilung auf das verwitterungsverhalten ausgewahlter sandsteine. Bautenschutz und Bausanierung 5:97-103

Flatt RJ (2002) Salt damage in porous materials: How high supersaturations are generated. J Cryst Growth 242:435-454. https://doi. org/10.1016/S0022-0248(02)01429-X

Goudie AS, Viles HA (1997) Salt weathering hazards. John Wiley, Chichester

Grementieri L, Daghia F, Molari L et al (2017) A multi-scale approach for the analysis of the mechanical effects of salt crystallisation in porous media. Int J Solids Struct 126-127:225-239. https://doi. org/10.1016/j.ijsolstr.2017.08.009

ISO 12571:2013 Hygrothermal performance of building materials and products - Determination of hygroscopic sorption properties

Lopez-Arce P, Garcia-Guinea J, Benavente D et al (2009) Deterioration of dolostone by magnesium sulphate salt: An example of incompatible building materials at Bonaval Monastery, Spain. Constr Build Mater 23:846-855. https://doi.org/10.1016/j.conbu ildmat.2008.04.001 
Lubelli B, Cnudde V, Diaz-Goncalves T et al (2018) Towards a more effective and reliable salt crystallization test for porous building materials: state of the art. Mater Struct Constr 51:1-21. https:// doi.org/10.1617/s11527-018-1180-5

McMahon DJ, Sandberg P, Folliard K, Mehta PK (1992) Deterioration mechanisms of sodium sulfate. In: Rodriques JD, Hendriques F, Jeremisas FT (eds.) Proceedings of 7th international congress of deterioration and conservation of stone, vol 2. Laboratorio Nacional de Engenharia Civil, Lisbon, pp 705-714

Nicholson DT (2001) Pore properties as indicators of breakdown mechanisms in experimentally weathered limestones. Earth Surf Process Landforms 26:819-838. https://doi.org/10.1002/esp.228

Nicholson DT (2002) Quantification of rock breakdown for experimental weathering studies. In: Prikryl R, Viles H (eds) Understanding and managing stone decay. Karolinum Press, Czech Republic, pp $115-130$

Ordóñez S, Fort R, García Del Cura MA (1997) Pore size distribution and the durability of a porous limestone. Q J Eng Geol 30:221-230

Prikryl R, Lokajíček T, Svobodová JW (2003) Experimental weathering of marlstone from Přední Kopanina (Check Republic) - historical building stone of Prague. Build Environ 38:1163-1171

Puehringer J (1983) Salt disintegration Salt migration and degradation by salts - a hypothesis. Swedish Council for Building Research, Stockholm

Robinson DA, Williams RBG (2000) Experimental weathering of sandstone by combinations of salts. Earth Surf Process Landforms 25:1309-1315. https://doi.org/10.1002/1096-9837(20001 1)25:12<1309:AID-ESP139>3.0.CO;2-5

Rodriguez-Navarro C, Doehne E, Sebastian E (2000) How does sodium sulfate crystallize? Implications for the decay and testing of building materials. Cem Concr Res 30:1527-1534. https://doi. org/10.1016/S0008-8846(00)00381-1

Ruedrich J, Siegesmund S (2007) Salt and ice crystallization in porous sandstones. Environ Geol 52:225-249

Ruiz-Agudo E, Mees F, Jacobs P, Rodriguez-Navarro C (2007) The role of saline solution properties on porous limestone salt weathering by magnesium and sodium sulfates. Environ Geol 52:305-317. https://doi.org/10.1007/s00254-006-0476-x

Scherer GW (2004) Stress from crystallization of salt. Cem Concr Res 34:1613-1624

Schiro M, Ruiz Agudo E, Jroundi F, et al (2012) Conservation of porous materials affected by salt weathering by means of in situ generation of biominerals and organic biofilms. In: Proceedings of the 12th International Congress on the Deterioration and Conservation of Stone, Columbia University, New York

Scrivano S, Gaggero L, Gisbert Aguilar J (2019) An Experimental investigation of the effects of grain size and pore network on the durability of vicenza stone. Rock Mech Rock Eng. https://doi. org/10.1007/s00603-019-01768-x

Scrivano S, Gaggero L, Gisbert Aguilar J (2018) Micro-porosity and minero-petrographic features influences on decay: Experimental data from four dimension stones. Constr Build Mater 173:342349. https://doi.org/10.1016/j.conbuildmat.2018.04.041
Siedel H (2018) Salt efflorescence as indicator for sources of damaging salts on historic buildings and monuments: a statistical approach. Environ Earth Sci. https://doi.org/10.1007/s12665-018-7752-4

Siegesmund S, Snethlage R (2014) Stone in architecture: Properties, durability: Fifth edition. Springer-Verlag Berlin Heidelberg. https ://doi.org/10.1007/978-3-642-45155-3

Smith BJ, Warke PA, McGreevy JP, Kane HL (2005) Salt-weathering simulations under hot desert conditions: agents of enlightenment or perpetuators of preconceptions. Geomorphology 67:211-227

Sousa LMO, Suárez del Río L, Calleja M, Ruiz de Argandoña L, Rodríguez Rey A (2005) Influence of microfractures and porosity on the physico-mechanical properties and weathering of ornamental granites. Eng Geol 77:153-168

Steiger M (2005) Crystal growth in porous materials - I: The crystallization pressure of large crystals. J Cryst Growth 282:455-469. https://doi.org/10.1016/j.jcrysgro.2005.05.007

Sun Q, Zhang Y (2019) Combined effects of salt, cyclic wetting and drying cycles on the physical and mechanical properties of sandstone. Eng Geol 248:70-79

Török Přkryl ÁR (2010) Current methods and future trends in testing, durability analyses and provenance studies of natural stones used in historical monuments. Eng Geol 115:139-142. https://doi. org/10.1016/j.enggeo.2010.07.003

Tsui N, Flatt RJ, Scherer GW (2003) Crystallization damage by sodium sulfate. J Cult Herit 4:109-115. https://doi.org/10.1016/S1296 -2074(03)00022-0

UNI EN 12370:2001 natural stone test methods - Determination of resistance to salt crystallization

UNI EN 13919:2002 Natural stone test methods - Determination of resistance to ageing by SO2 action in the presence of humidity

UNI EN 14147:2003 Natural stone test methods - Determination of resistance to ageing by salt mist

UNI EN 15801:2010 Conservation of cultural property - test methods - Determination of water absorption by capillarity

Yavuz AB, Topal T (2007) Thermal and salt crystallization effects on marble deterioration: Examples from western Anatolia, Turkey. Eng Geol 90:30-40

Yu S, Oguchi CT (2010) Role of pore size distribution in salt uptake, damage, and predicting salt susceptibility of eight types of Japanese building stones. Eng Geol 115:226-236. https://doi. org/10.1016/j.enggeo.2009.05.007

Zedef V, Kocak K, Doyen A et al (2007) Effect of salt crystallization on stones of historical buildings and monuments, Konya, Central Turkey. Build Environ 42:1453-1457

Publisher's Note Springer Nature remains neutral with regard to jurisdictional claims in published maps and institutional affiliations. 